\title{
Rural Road Reverse Engineering Using Bim: an Italian Case Study
}

\author{
Francesco Abbondati (iD ${ }^{*}$, Cristina Oreto (iD) 2 , Nunzio Viscione (iD 3 , \\ Salvatore Antonio Biancardo (iD 4 \\ ${ }^{1}$ Department of Engineering, University of Naples Parthenope, Naples, Italy \\ ${ }^{2,4}$ Department of Civil, Construction and Environmental Engineering, \\ Federico II University of Naples, Naples, Italy \\ ${ }^{3}$ Iterchimica Srl, Suisio, Bergamo, Italy
}

Received 20 April 2020; accepted 03 May 2020

\begin{abstract}
The use of Building Information Modeling (BIM) is changing the way to perceive, manage and maintain any infrastructural project. The concept of Smart Roads relaunches the transport infrastructure sector through the digital transformation, able to create lean, quality, safer and cheaper infrastructures. The reverse engineering parametric modeling process was applied to "SS18 VAR" rural road, one of the main viabilities in Southern Italy. The case study was developed in according to the following steps: a) creating Digital Terrain Model (DTM); b) modeling horizontal alignment-vertical profiles; c) modeling 3D Corridor; d) modeling Viaducts; e) creating realistic 3D rendering. Bentley Systems software ${ }^{\circledR}$ were used in this study. The case study provided interesting elements to evaluate the advantages and disadvantages of design practice through BIM style tools, as well as the current state of the methodology itself.
\end{abstract}

Keywords: Infrastructure-Building Information Modelling (I-BIM), parametric modelling, viaducts, real world context, smart roads, Southern Italy.

\section{Introduction}

The acronym I-BIM is used in the Architecture, Engineering and Construction (AEC) sector to identify BIM applications in the infrastructure field. The widespread use of BIM in construction has generated growing interest also in I-BIM applications (Dell'Acqua, 2015; Dell'Acqua et al., 2018b). I-BIM is a complex system of procedures and technologies for the management of infrastructure processes. Unlike Computer Aided Design and Drafting (CADD), which substantially automates aspects of the traditional production of drawings, BIM methodology represents a change of paradigm (Osello, 2012). This methodology allows to transform simple drawings into intelligent objects with specific properties and detailed information, in order to simplify and accelerate the design and construction of any work (Eastman et al., 2016). In Italy, the UNI 11337 Standard regulates the use of digital processes in construction field. This Standard is made up of 10 parts, but currently only 5 parts (1, 4, 5, 6 and 7) are already published. Part 1 (Ente Italiano di Normazione, 2017) defines the concept of information models and documents. The information document is the two-dimensional or three-dimensional paper representation of the design idea. Then the design idea is shared between the different actors who collaborate on a project through paper documents. The information model, on the other hand, represents the three-dimensional virtual model that will be shared between the various Stakeholders through a specific platform. Part 4 (Ente Italiano di Normazione, 2017) defines the evolution and information development of models, designs and objects. Part 5 (Ente Italiano di Normazione, 2017) defines the logical scheme of the flows needed for the production, management and transmission of information. In Part 6 (Ente Italiano di Normazione, 2017), the examples and standards for the Information Specifications are defined. Part 7 (Ente Italiano di Normazione, 2017), approved in January 2019, defines the professional roles for information management and modeling. The CDE Manager is the manager of the data sharing environment, which guarantees the correctness and timeliness of the flow of information between the parties involved. It applies data analysis and protection techniques and promotes the interoperability of information models and job order data. The BIM Manager is the manager of the digitized processes at the organization level and has general supervision of company orders. It defines and ensures the rules for the implementation of the organization's processes for the management of information flows and the use of the CDE for each individual job. He draws up the Information document, the Information Management offer, and every contractual aspect relating to the management of the order. The BIM Coordinator is the coordinator of the information

*Corresponding author. E-mail: francesco.abbondati@ uniparthenope.it 
flows and of the company's BIM Specialist team, which acts as guarantor of the efficiency and effectiveness of the digitized processes with reference to the specific order. He has a multidisciplinary competence and supports Bim Manager in the drafting of the information specifications or information management offer. The BIM Specialist is the operator of the information modeling, competent in one of the different disciplines, who works within the individual orders able to use the technical documentation and dedicated software for the modeling of the objects and the production of the works. For the profile of the BIM Specialist only, it is necessary to choose the disciplinary area of competence between architecture, structure, systems, and infrastructure. Electronic tools were introduced in Italy with the Legislative Decree n. 50 of April 18, 2016 (President of the Republic, 2016) which implements the EU directives 24/2014 (European Parliament and of the Council, 2014) "on the award of concession contracts, public contracts and procurement procedures of the providers in the water, energy, transport and postal services sectors, as well as for the reorganization of the current regulations on public contracts relating to works, services and supplies". The Law Decree n. 560 of December 1, 2017 (Ministry of Infrastructures and Transport, 2018) establishes the methods and times of progressive introduction of the electronic modeling methods and tools for construction and infrastructure. In particular, starting from 2019 BIM methodology become a mandatory for all works with an amount of 100 million euros. This obligation will extend for complex works over 50 million euros by 2020, passing then to complex works over 15 million euros by 2021, for works over 1 million euros by 2023 and by 2025 for all works. The performance specifications to be applied in the infrastructure digital transformation process determine the attribution of the Smart Roads qualification to the infrastructures. Smart Roads means the set of technologies that goes from the creation to the management and maintenance of transport with the use of techniques capable of making roads safer, smart, innovative and sustainable through a digital transformation process (Ministry of Infrastructure and Transport, 2017). The 3D digital transformation of road infrastructure can also be extended to time analysis (BIM 4D), cost management (BIM 5D) and finally to road maintenance management (BIM 7D). The parametric modeling (on which all BIM Authoring software are based) allows to define intelligent objects whose informative content is based not only on geometric characteristics but also on physical-mechanical characteristics as well as on construction times and costs; in this way it is possible to create a real avatar of the work that allows you to monitor the entire life cycle of the work (Abbondati et al., 2016, 2020; Biancardo et al., 2018, 2019, 2020a, 2020b; Russo \& Biancardo, 2017; Russo et al., 2018; Veropalumbo et al., 2020). Moreover, with the creation of the three-dimensional virtual model of the work, it is possible to identify a series of problems during the design phase. For example, through clash detection, it is possible to superimpose the individual different models (architectural, structural, M\&E systems) and perform the analysis of geometric interference (an operation that with the traditional methodology would not be possible) thus reducing construction time.

Currently, in the state of the art, there is a lack of I-BIM applications. The move from 2D drawings to 3D models is explored in this case study showing how BIM technology provides explicit design of information available to all stakeholders who are then able to support decision-making initiatives through better management, use and sharing of information.

\section{Case Study}

\subsection{Territorial context}

SSVAR 18 is on the major rural road in Southern Italy, connecting Campania to Calabria Region. The BIM reverse engineering case study focuses on the part between Futani and Poderia Municipalities in Cilento (Figure 1). The road section has an extension of approximately $9 \mathrm{~km}$, with a lane width of $3.75 \mathrm{~m}$ and shoulders of $1.50 \mathrm{~m}$.

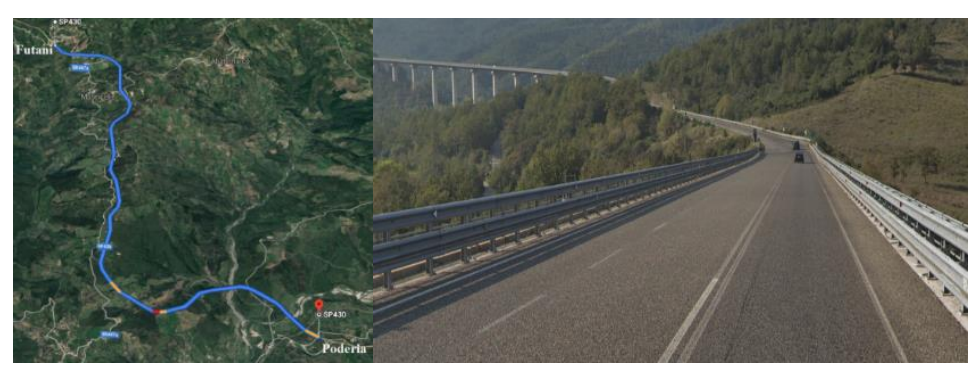

Figure 1. Overview of the SS18 VAR Futani-Poderia

The case study was carried out using Open Roads Designer ${ }^{\circledR}$, LEAP Bridge Concrete ${ }^{\circledR}$ and LumenRT ${ }^{\circledR}$ Bentley Systems Software as follows: a) modeling of the terrain surface; b) modeling horizontal alignment and vertical profile; c) modeling $3 \mathrm{D}$ corridor; d) modeling viaducts; e) realistic 3D rendering. 


\subsection{Modeling Terrain}

Starting from the Regional Technical cartography, composed by level curves and elevations points, the DTM was created as shown in Figure 2 using a Triangulated Irregular Network (TIN). The TIN model represents a surface as a set of contiguous, non-overlapping triangles. Within each triangle the surface is represented by a plane. The triangles are made from a set of points called mass points.

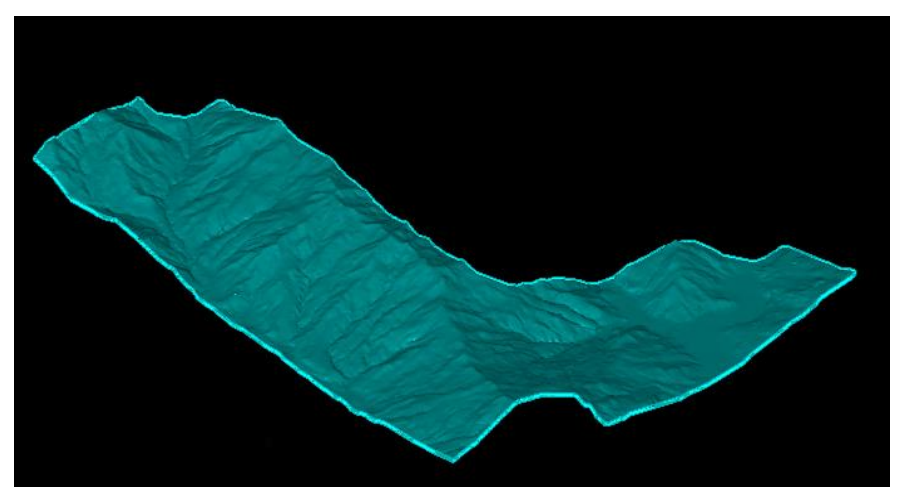

Figure 2. Digital Terrain Model of the investigated area

\subsection{Horizontal alignment and vertical profile}

The horizontal alignment, shown in Figure $3 \mathrm{a}$, is composed by 14 tangent elements and 13 circular curves, with a presence of 2 viaducts and 3 overpasses. No spiral curves (clotoids) were observed, since the investigated road was built before the entry into force of the current Design Standards (Ministry of Infrastructures, 2001) that regulated the use of these elements. The design speed range is $60-100 \mathrm{~km} / \mathrm{h}$. The relative vertical profile, composed by 2 crests and 2 sags is shown in Figure $3 b$.

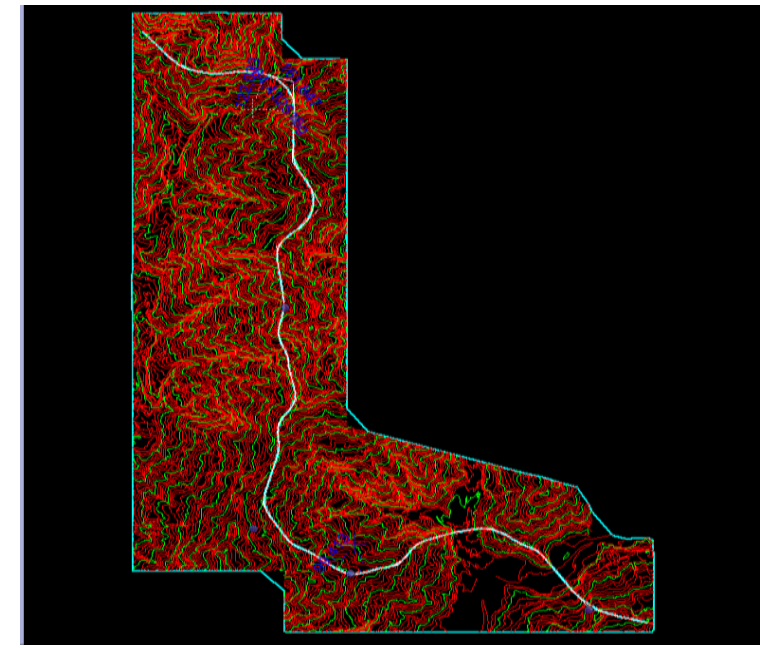

a)

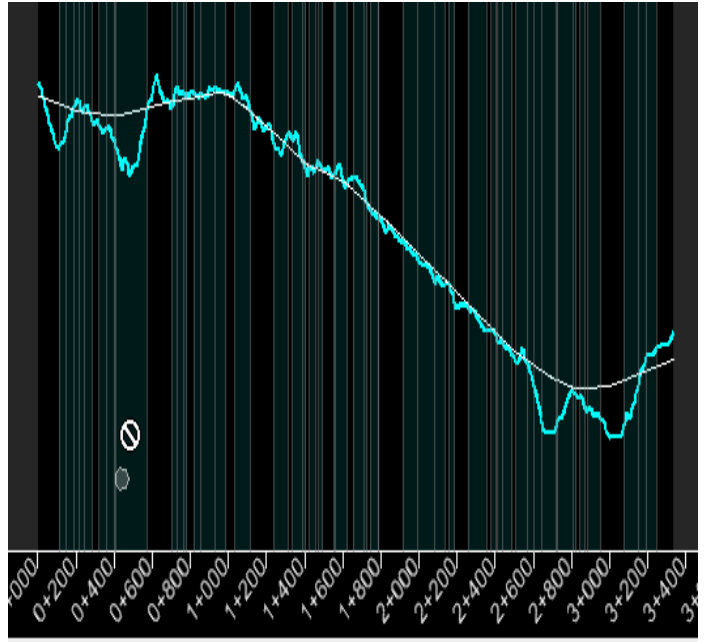

b)

Figure 3. SS18 VAR Futani-Poderia: a) Horizontal alignment; b) Vertical profile

\subsection{Modeling 3D Corridor}

The assembly template was edited in according to the geometric features of the investigated road (Figure 4a). The assembly template is characterized by a series of points called features. The features points include also functional and mechanical characteristics, such as material type with the relative mechanical strengths. This modeling is also called ordered, because each feature has three degrees of freedom indicated by the colours: red, yellow and green (Figure 4b). Green indicates an unconstrained feature with the possibility of translations and rotations; yellow indicates a partially constrained feature, while red indicates a fully constrained feature. Therefore, by associating a green feature with the road axis and the red features with all the other elements, it is possible to link each road component to the axis. In this way, all changes made to the axle will be automatically made to the entire road solid. 


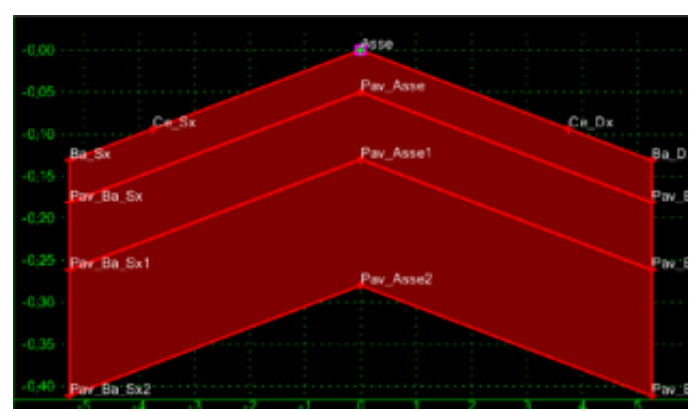

a)

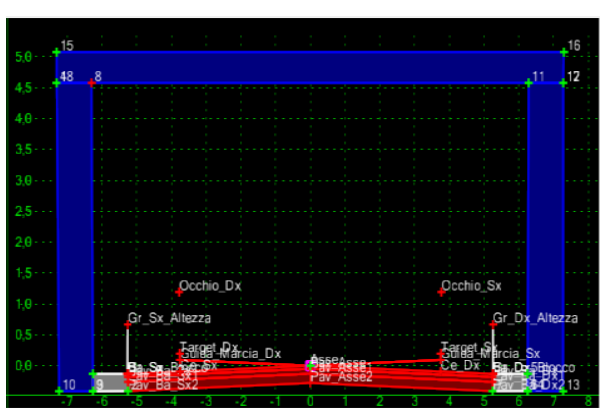

b)

Figure 4. Assembly Template: a) pavement structure; b) features points in presence of viaduct (b)

Once the standard template for cross sections was defined, the 3D corridor was generated as shown in Figure 5.

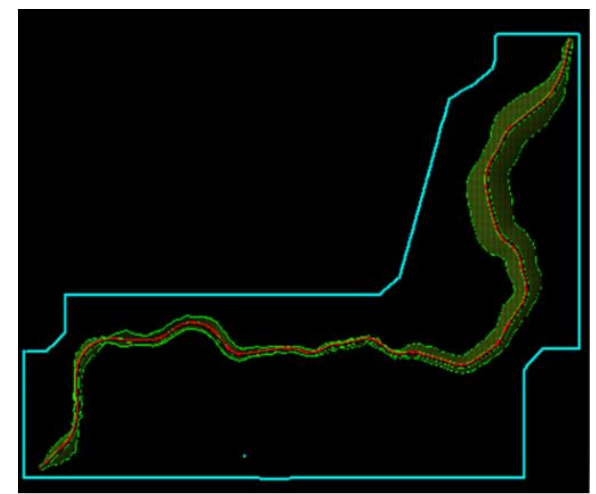

Figure 5. SS18 VAR Futani-Poderia 3D Corridor

From the 3D model it is possible to extract the view of the cross sections with cut/fill volume indication (Figure 6). According to the current Design Standard (Ministero delle Infrastrutture e dei Trasporti, 2001), the design criteria were checked regarding stopping distance visibility and visibility in curves.

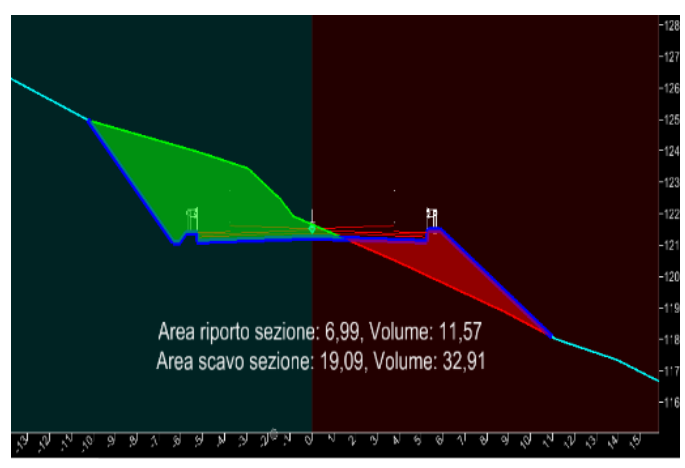

a)

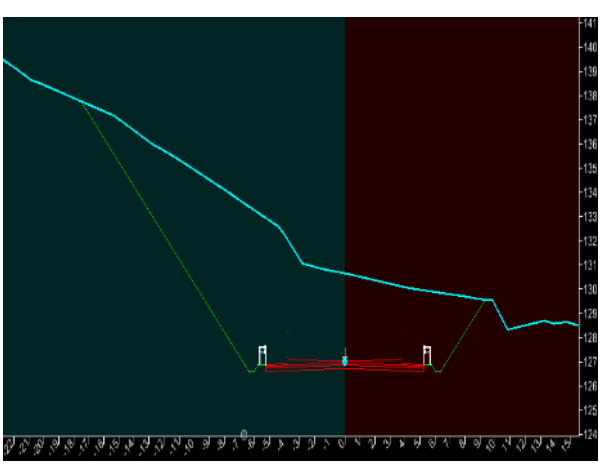

b)

Figure 6. Cross section view: a) half-rib; b) cut (b)

\subsection{Geometric and structural modeling of viaducts}

The 3 viaducts have been modeled with LEAP Bridge Concrete ${ }^{\circledR}$ Bentley Systems Software, defining the geometry of the decks, beams and piles (Figure 7a). At the end of the preliminary modeling phase, an analysis of the loads and stresses was performed (Figure $7 b$ ) and based on the obtained values, the design and verification of each structural element was carried out in according to the specific Standard (Ministry of Infrastructure, 2018). 


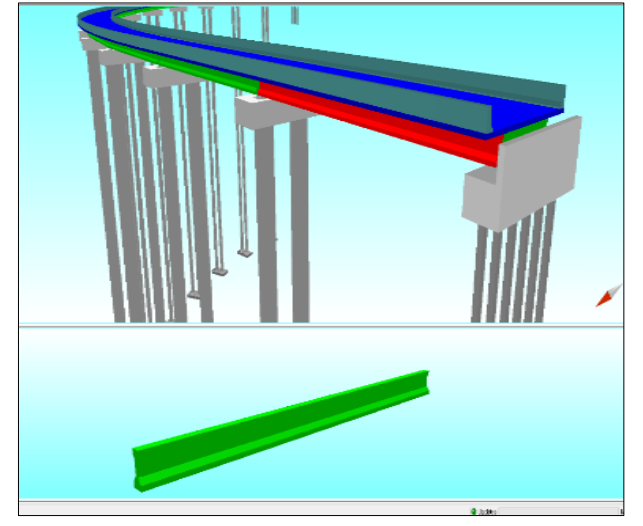

a)

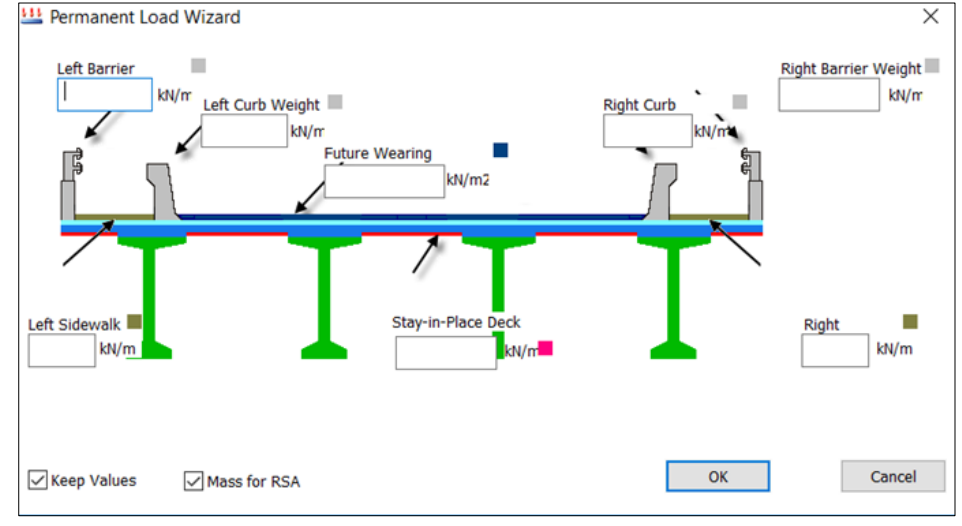

b)

Figure 7. Viaducts modeling: a) beams; b) deck

\subsection{Realistic 3D rendering}

In order to improve the graphic rendering of the entire project and get a more realistic view of the case study, LumenRT ( $)$ Bentley Systems Software was used. The results are shown in Figure 8.

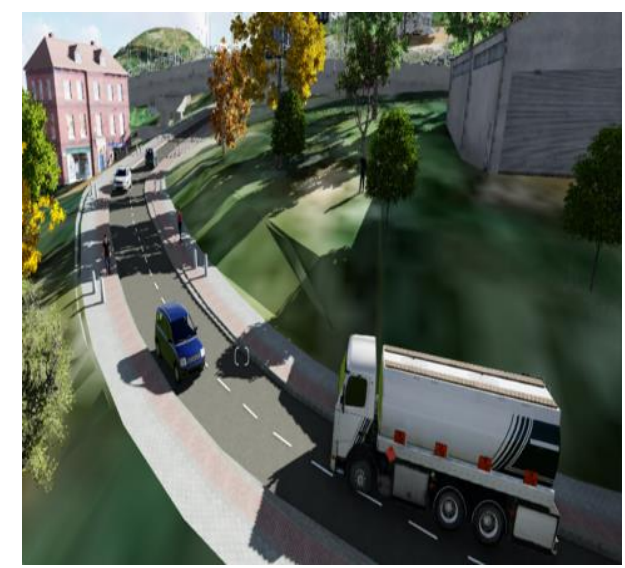

a)

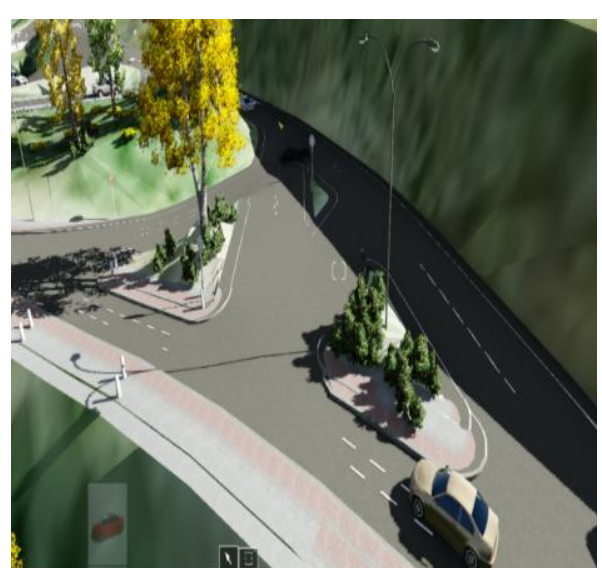

b)

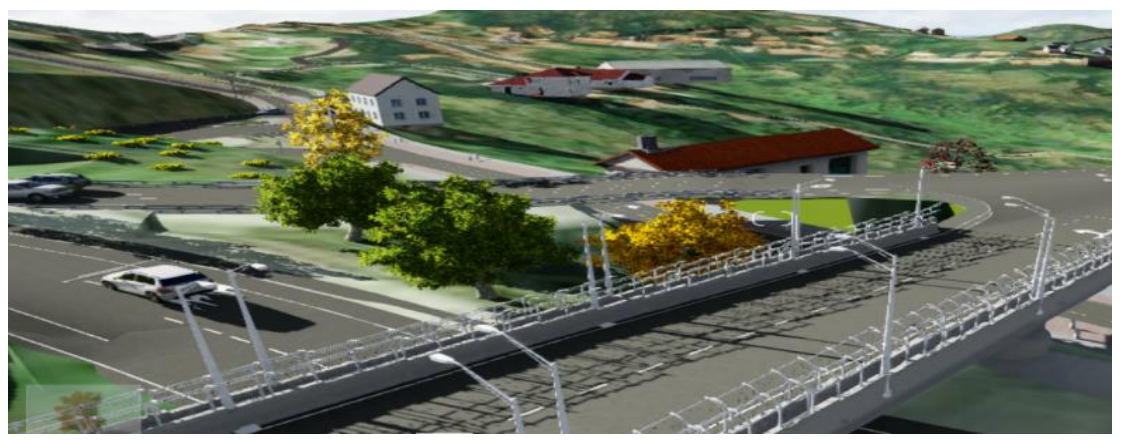

c)

Figure 8. 3D rendering: a) in a curve; b) at intersection: c) on a viaduct

\section{Conclusions}

BIM metolology facilitates and accelerates the process from the conception to the realization of the work as well as gives greater certainty to the whole realization allowing all the actors of the construction process to participate in the conception of the work from the earliest stages (Dell'Acqua et al., 2018a). In this work, a case of reverse engineering was presented in order to digitize an existing road. The case study provided some interesting elements to evaluate the advantages and disadvantages of design practice through BIM-style tools, as well as the current state of the methodology itself. First of all, despite the fact that the starting cartography has limited information due to its scale, it has been possible to proceed with the reconstruction of the existing route with good precision and considerable level 
of detail, through consequential parametric operations, able to ease the transition from graphic objects to "intelligent" objects, thus simplifying the process, and streamlining the modification times and, consequently, the realization of the elaborate. It is clear how, by having more detailed starting data, such as the thickness of the road superstructure layers or the connecting lengths of the constant scope, it is possible to obtain a better final result and with even fewer approximations. It is necessary to take into account some aspects that can be improved on the calculation code we used. First of all, it requires considerable processing and graphics hardware resources, not always supported, thus making operations slow especially after the creation of the model. It is therefore preferable to break the layout into several worksheets in order to minimize the slowdowns due to the load of parameters in the modeler. Furthermore, the generated worksheets have a considerable amount of data inside them and for this reason their dimensions are about ten times higher than the files generated with traditional CAD-type calculation codes.

\section{Funding}

This research received no specific grant from any funding agency in the public, commercial, or not-for-profit sectors.

\section{Author contributions}

All the Authors carried out the concept of the research. CO and NV were responsible for Introduction. FA, SAB were responsible for data processing and visualization. FA wrote the first draft of paper. SAB revised the final draft of the paper.

\section{Disclosure statement}

The authors declare that don't have any competing financial, professional, or personal interests from other parties.

\section{References}

Abbondati, F., Biancardo, S. A., Palazzo, S., Capaldo, F. S., \& Viscione, N. (2020). I-BIM for Airport Infrastructures. Transportation Research Procedia, 45, 596-603. https://doi.org/10.1016/j.trpro.2020.03.052

Abbondati, F., Capaldo, F. S., Biancardo, S. A., \& Mancini, L. (2016). Descriptors in scenic low-volume roads analysis through visual evaluation. ARPN Journal of Engineering and Applied Sciences, 11(23), 13845-13855.

Biancardo, S. A., Abbondati, F., Russo, F., Veropalumbo, R., \& Dell'Acqua, G. (2020a). A broad-based decision-making procedure for runway friction decay analysis in maintenance operations. Sustainability, 12(9), 3516. https://doi.org/10.3390/su12093516

Biancardo, S. A., Capano, A., Oliveira, S. G., \& Tibaut, A. (2020b). Integration of BIM and procedural modeling tools for road design. Infrastructures, 5(4), 37. https://doi.org/10.3390/infrastructures5040037

Biancardo, S. A., Russo, F., Zhang, W., \& Veropalumbo, R. (2019). Design criteria for improving safety performance of rural intersections. Journal of Advanced Transportation, 2019, 1232058. https://doi.org/10.1155/2019/1232058

Biancardo, S. A., Zhang, W., \& Coraggio, G. (2018). BIM reverse engineering: digital transformation of existing roads. Proceedings of the ICTTE 2018 - The International Conference on Traffic and Transport Engineering, Belgrade, Serbia, 584-591.

Dell'Acqua, G. (2015). Modeling driver behavior by using the speed environment for two-lane rural roads. Transportation Research Record, 2472(1), 83-90. https://doi.org/10.3141/2472-10

Dell'Acqua, G., De Luca, M., \& Zilioniene, D. (2018a). Using artificial neural network and multivariate analysis techniques to evaluate road operating conditions. Journal of Risk Research, 21(6), 679-691. https://doi.org/10.1080/13669877.2016.1264445.

Dell'Acqua, G., De Oliveira, S. G., \& Biancardo, S. A. (2018b). Railway-BIM: Analytical review, data standard and overall perspective. Ingegneria Ferroviaria, 11, 901-923.

Eastman, C., Teicholz, P, Sacks, R., \& Liston, K. (2016). BIM Handbook: A guide to building information modeling for owners, managers, designers, engineers and contractors. John Wiley \& Sons Inc.

Ente Italiano di Normazione. (2017). Norma UNI 11337-1:2017 - Edilizia e opere di ingegneria civile - Gestione digitale dei processi informativi delle costruzioni - Parte 1: Modelli, elaborati e oggetti informativi per prodotti e processi.

Ente Italiano di Normazione. (2017). Norma UNI 11337-4:2017 - Edilizia e opere di ingegneria civile - Gestione digitale dei processi informativi delle costruzioni - Parte 4: Evoluzione e sviluppo informativo di modelli, elaborati e oggetti.

Ente Italiano di Normazione. (2017). Norma UNI 11337-5:2017 - Edilizia e opere di ingegneria civile - Gestione digitale dei processi informativi delle costruzioni - Parte 5: Flussi informativi nei processi digitalizzati.

Ente Italiano di Normazione. (2017). Norma UNI 11337-6:2017 - Edilizia e opere di ingegneria civile - Gestione digitale dei processi informativi delle costruzioni - Parte 6: Linea guida per la redazione del capitolato informativo.

Ente Italiano di Normazione. (2017). Norma UNI 11337-7:2017 - Edilizia e opere di ingegneria civile - Gestione digitale dei processi informativi delle costruzioni - Parte 7: Requisiti di conoscenza, abilità e competenza delle figure coinvolte nella gestione e nella modellazione informativa. 
European Parliament and of the Council. (2014). Directive 2014/24/EU of the European Parliament and of the Council 2014. Official Journal of the European Union. http://procurement.gov.ge/getattachment/ELibrary/UsefulResources/CELEX32014L0024-EN-TXT.pdf.aspx

Ministero delle Infrastrutture e dei Trasporti. (2001). Decreto Ministeriale 5 novembre 2001, n. 6792 (S.O. n.5 alla G.U. n.3. del 4.1.02) Norme funzionali e geometriche per la costruzione delle strade. http://www.mit.gov.it/mit/mop_all.php?p_id=1983

Ministero delle Infrastrutture e dei Trasporti. (2017). Standard funzionale per le Smart Road. http://www.mit.gov.it/sites/default/files/media/notizia/201606/Standard\%20funzionali\%20per\%20le\%20Smart\%20Road.pdf

Ministero delle Infrastrutture e dei Trasporti. (2018). Decreto Ministeriale n. 560 del 01/12/2017. http://www.mit.gov.it/sites/default/files/media/normativa/201801/Decreto\%20Ministro\%20MIT\%20n.\%20560\%20de1\%201.12.2017.pdf

Ministero delle Infrastrutture. (2018). Nuove Norme Tecniche per le Costruzioni. Decreto Ministeriale 17 gennaio 2018. https://www.gazzettaufficiale.it/eli/id/2018/2/20/18A00716/sg

Osello, A. (2012). Il futuro del disegno con il BIM per Ingegneri e Architetti. Dario Flaccovio Editore.

Presidente della Repubblica. (2016). Decreto Legislativo 18 Aprile 2016, N. 50. https://www.codiceappalti.it/documenti/CodiceAppalti.it_Ultimo_aggiornamento.pdf.

Russo, F., \& Biancardo, S. A. (2017). Countermeasures to improve road alignment consistency of undivided rural roads. The Baltic Journal of Road and Bridge Engineering, 12(4), 211-217. https://doi.org/10.3846/bjrbe.2017.26

Russo, F., Biancardo, S. A., Formisano, A., \& Dell'Acqua, G. (2018). Predicting percent air voids content in compacted bituminous hot mixture specimens by varying the energy laboratory compaction and the bulk density assessment method. Construction and Building Materials, 164(10), 508-524. https://doi.org/10.1016/j.conbuildmat.2017.12.174

Veropalumbo, R., Russo, F., Viscione, N., \& Biancardo, S. A. (2020). Rheological properties comparing hot and cold bituminous mastics containing jet grouting waste. Advances in Materials Science and Engineering, 2020, 8078527. https://doi.org/10.1155/2020/8078527

\title{
Notations
}

\author{
Abbreviations \\ BIM - Building Information Modeling \\ CADD - Computer Aided Design and Drafting \\ CDE - Common Data Environment \\ DTM - Digital Terrain Model \\ I-BIM - Infrastructure-Building Information Modeling \\ TIN - Triangulated Irregular Network \\ UNI - Ente Nazionale Italiano di Unificazione \\ 3D - Three-dimensional \\ 4D - Fuor-dimensional \\ 5D - Five-dimensional \\ 7D - Seven-dimensional
}

